\title{
Patient-reported intra-dialytic symptoms and post-dialysis recovery times are influenced by psychological distress rather than dialysis prescription
}

\author{
Suree Yoowannakul ${ }^{1}$, Kamonwan Tangvoraphonkchai ${ }^{2}$ and Andrew Davenport ${ }^{3 *}$
}

\begin{abstract}
Background: Dialysis is a life-sustaining treatment, but many patients suffer symptoms during dialysis and take time to recover. Previous reports have linked recovery time to intra-dialytic hypotension and rapid solute clearances, whereas others have reported an association with psychological factors. As such, we wished to investigate which factors were important in determining symptom self-reporting and delayed recovery times.

Methods: We recorded self-reported patient intra-dialytic symptoms, recovery times along with sessional dialysis prescriptions, blood pressure and urea clearance, and distress thermometer scores to assess psychological factors.

Findings: Six hundred twenty-three dialysis patients were studied; 621 treated by haemodiafiltration, $60.8 \%$ male, mean age $64.5 \pm 16.2$ years, and $46.1 \%$ diabetic. Almost half (49.6\%) reported recovery within $1 \mathrm{~h}$. On multivariate analysis, patient self-reported symptom scores were associated with longer post-dialysis recovery times (odds ratio (OR) 1.61, 95\% confidence limits (CL) 1.33-1.95), higher distress thermometer scores (OR 1.3 CL (1.3-1.39), but lower hand grip strength $(\mathrm{OR} 0.85 \mathrm{CL}(0.93-0.94)$, all $p<0.001$, and younger rather than older patients (OR $0.98 \mathrm{CL}(0.97-0.99)$ $p=0.005$. We found no association with ultrafiltration rates or weight loss.
\end{abstract}

Discussion: Compared to earlier studies, our patients treated by haemodiafiltration reported fewer symptoms and shorter recovery times. Patients with higher self-reported distress thermometer scores had both longer post-dialysis recovery times and greater dialysis symptom scores. Younger patients reported more dialysis symptoms and longer recovery times than older patients. Future studies investigating patient self-reported recovery times and dialysis-associated symptoms should also consider interventions to reduce patient psychological factors as well as dialysis practices.

Keywords: Haemodialysis, Distress thermometer, Hand grip strength, Cramps, Headaches

\section{Introduction}

Haemodialysis is a life-sustaining treatment for patients with end-stage kidney disease. Despite the many technological developments in dialysis over the past 50 years [1], patients often feel tired after dialysis and may take time to recover [2]. In addition, patients may also complain of other symptoms that occur with dialysis including muscle cramps, headache, pruritus, dizziness and nausea $[3,4]$.

\footnotetext{
* Correspondence: andrewdavenport@nhs.net

${ }^{3}$ UCL Department of Nephrology, Royal Free Hospital, Rowland Hill Street, London NW3 2PF, UK

Full list of author information is available at the end of the article
}

During dialysis, there are relatively rapid fluid and electrolyte shifts and changes in plasma osmolality [5]. Blood pressure may fall along with perfusion to internal organs, with hypotension being the most commonly reported complication of routine outpatient dialysis treatments [6]. Previous reports have linked various aspects of the dialysis prescription with intra-dialytic and post-dialysis symptom reporting, including the choice of dialysate sodium, potassium and temperature [7-9]. Whereas others have reported that the prevalence of intra-dialysis symptoms and post-dialysis fatigue is reduced by achieving greater urea clearance [10], or by changing from the standard thrice weekly dialysis schedule to shorter but more frequent

(C) The Author(s). 2019 Open Access This article is distributed under the terms of the Creative Commons Attribution 4.0 International License (http://creativecommons.org/licenses/by/4.0/), which permits unrestricted use, distribution, and 
daily dialysis sessions [11], or low-efficiency continuous dialysis [12]. Whether adding convective clearance or switching from haemodialysis to haemofiltration improves intra-dialytic symptoms and post-dialysis recovery times remains unclear, with some studies reporting a benefit and others no effect $[9,12,13]$.

Although many reports have suggested that dialysis factors are the most important in determining intra-dialytic symptoms and post-dialysis fatigue [14], others have suggested that patient factors are equal if not more important in determining self-reported dialysis-associated symptoms $[15,16]$. Due to the uncertainty $[17,18]$, we retrospectively investigated whether there was an association between intra-dialytic symptoms and time to recover post-dialysis and dialysis prescriptions, patient frailty and co-morbidity and patient psychological distress.

\section{Patients and methods}

As part of UK National Health Service guidelines to request patient feedback on treatment received, all patients attending for routine outpatient dialysis treatments under the care of a university hospital were asked to complete a questionnaire recording the frequency of dialysis-associated symptoms and time to recovery using a previously reported visual analogue scale $[4,14]$, and also a distress thermometer score, a screening tool for assessing psychological stress [19]. Hospital-computerised medical records were reviewed to obtain co-morbidity which had been recorded according to the Stoke-Davies grading [20] and frailty using the Canadian geriatric frailty score [21]. Hand grip strength (HGS) was measured using the grip-D strength dynamometer (Takei Scientific Instruments Co., Nigata, Japan) according to the manufacturer's instructions in the dominant arm, and the strongest of three measurements recorded [22].

Pre-midweek blood samples were taken for standard biochemical measurement of urea, creatinine, albumin, C-reactive protein (CRP) and $\mathrm{N}$ terminal pro-brain natriuretic peptide (NT-proBNP) (Roche Integra, Roche Diagnostics, Lewes, UK) [23], and haemoglobin along with the corresponding post-dialysis urea.

The dialysis prescription and dialysis session details were obtained from hospital computerised records. Patients were dialysed using either a Fresenius $4000 \mathrm{H}$, or $5008 \mathrm{H}$ dialysis machines (Fresenius MC, Bad Homburg, Germany), or BBraun Dialogue $^{+}$(BBraun, Melsungen, Germany) with a polysulphone dialyzer (Fresenius MC, Bad Homburg, Germany) [24] and anticoagulated with a bolus of tinzaparin low molecular weight heparin (Leo Laboratories, Princes Risborough, UK) [25]. All dialysates had a set final concentration or $32 \mathrm{mmol} / \mathrm{L}$ of bicarbonate, $3.0 \mathrm{mmol} / \mathrm{L}$ acetate, magnesium $0.5 \mathrm{mmol} / \mathrm{L}$ and glucose $5.5 \mathrm{mmol} / \mathrm{L}$. Conductivity modules were regularly calibrated and delivered dialysate sodium checked by both flame photometry and ion electrophoresis methods [26, 27].

\section{Ethics}

This retrospective audit complied with the UK National Health Service guidelines for clinical audit and service development and met with the approval from the Health Research Authority. In keeping with UK guidelines, all patient data were anonymised prior to analysis (www.hra.nhs.uk).

\section{Statistical analysis}

Data is presented as mean \pm standard deviation, median (interquartile range) or as a percentage. Standard statistical tests were used to analyse data, (D’Agostino-Pearson normality test, ANOVA, Kruskal-Wallis, or chi-square test) with appropriate corrections made for multiple testing, where appropriate (Tukey or Gannet-Howell). Univariate correlation used Spearman analysis. Multivariable logistic regression analysis was performed using a step backward approach, using all variables with a $p<0.1$ correlation, and then, variables were excluded if not statistically significant, unless they improved the model fit. Models were checked for collinearity between variables. Statistical analysis used Prism 8.0 (GraphPad, San Diego, USA) and Social and Political Sciences statistical package (SPSS 24.0, IBM, Armonk, USA). Statistical significance was taken as $p<0.05$.

\section{Results}

Six hundred fifty-three adult outpatients attended for dialysis out of a possible 668, with 15 patients absent either admitted to hospital or on-holiday, and 623 (95.4\%) completed the dialysis symptom and distress thermometer questionnaire. Ten patients were unable to understand the visual analogue scores due to their inability to understand English, 4 because of dementia or other mental illness and 16 either due to poor visual acuity or declined to participate.

Patient demographics are set out in Table 1. All but two patients were treated by post-dilutional haemodiafiltration. Patients were asked to record the frequency of dialysis-associated symptoms on a Likert visual analogue scale from zero to ten, and the most frequent symptom was tiredness followed by feeling cold, then cramps and symptoms associated with low blood pressure, pruritus and dizziness (Fig. 1). Patients were also asked to score their recovery time post-dialysis, with most patients reporting recovery with an hour (Fig. 2). Patients with higher intra-dialytic symptom scores had longer post-dialysis recovery times (Fig. 3).

On univariate analysis, greater symptom scores were associated with greater distress thermometer scores, longer time to recover, female gender, weaker hand grip strength, younger age, past medical history of hypertension, higher dialysis sessional urea reduction ratio, higher CRP, greater fall in systolic blood pressure during 
Table 1 Patient demographics of 623 adult patients with chronic kidney disease attending for routine outpatient haemodiafiltration treatment. Patient demographics, dialysis prescription, co-morbidity and muscle strength. Results displayed as integers, percentage, mean \pm standard deviation or median and interquartile range

\begin{tabular}{|c|c|}
\hline Variable & Results \\
\hline Male gender & $379(60.8)$ \\
\hline Age, years & $64.5 \pm 16.2$ \\
\hline Diabetic & $287(46.1)$ \\
\hline Ethnicity, White & $269(43.2)$ \\
\hline Ethnicity, Black & $202(32.4)$ \\
\hline Ethnicity, Asian & $149(23.9)$ \\
\hline Age, years & $64.5 \pm 16.2$ \\
\hline Venous catheter, access & $147(23.6)$ \\
\hline Arterio-venous fistula/graft access & $445(71.4) / 31(5.0)$ \\
\hline Pre-dialysis weight, kg & $71.5(61.8-83.9)$ \\
\hline Post-dialysis weight, kg & $70.0(60.7-82.1)$ \\
\hline Ultrafiltration rate, $\mathrm{mL} / \mathrm{kg} . \mathrm{h}$ & $6.0(3.9-8.0)$ \\
\hline Convection volume, L & $19.1(16.0-23.0)$ \\
\hline Urea reduction ratio, \% & $74.6(69.3-78.9)$ \\
\hline Dialysis session time, $\mathrm{h}$ & $4.0(3.5-4.0)$ \\
\hline Dialysate sodium, mmol/L & $136(136-138)$ \\
\hline Dialysate potassium, mmol/L & $2.0(1.0-2.0)$ \\
\hline Dialysate calcium, mmol/L & $1.0(1.0-1.25)$ \\
\hline Dialysate temperature, ${ }^{\circ} \mathrm{C}$ & $35.5 \pm 0.7$ \\
\hline Dialyzer surface area, $\mathrm{m}^{2}$ & $2.10(1.8-2.2)$ \\
\hline Tinzaparin, IU & $2500(2500-2500)$ \\
\hline Serum sodium, mmol/L & $139 \pm 3.6$ \\
\hline Serum urea, mmol/L & $18.2 \pm 5.8$ \\
\hline Serum creatinine, umol/L & $690(547-861)$ \\
\hline C-reactive protein, mg/L & $6.0(2.0-11.0)$ \\
\hline Serum albumin, $g / L$ & $39(36-41)$ \\
\hline Haemoglobin, g/L & $108.0 \pm 14.3$ \\
\hline Serum pro-brain natriuretic peptide, ng/L & $5635(1566-11,953)$ \\
\hline Glycated haemoglobin, mmol/mol & $47.5(37.7-61.7)$ \\
\hline Blood sugar, mmol/L & $6.5(5.4-8.2)$ \\
\hline Prescribed antihypertensives & $375(60.2)$ \\
\hline Myocardial infarction & $115(18.5)$ \\
\hline Coronary artery bypass, surgery/stenting & $43(6.9) / 58(9.3)$ \\
\hline Peripheral vascular disease & $90(16.4)$ \\
\hline Renal artery stenosis/aortic aneurysm & $24(3.9)$ \\
\hline Transient ischaemic attack & $19(3.1)$ \\
\hline Cerebrovascular accident & $65(10.4)$ \\
\hline Cancer & $104(16.7)$ \\
\hline Frailty & $4(3-5)$ \\
\hline Distress thermometer & $3(0-6)$ \\
\hline Hand grip strength, kg & $20.4 \pm 10.5$ \\
\hline
\end{tabular}

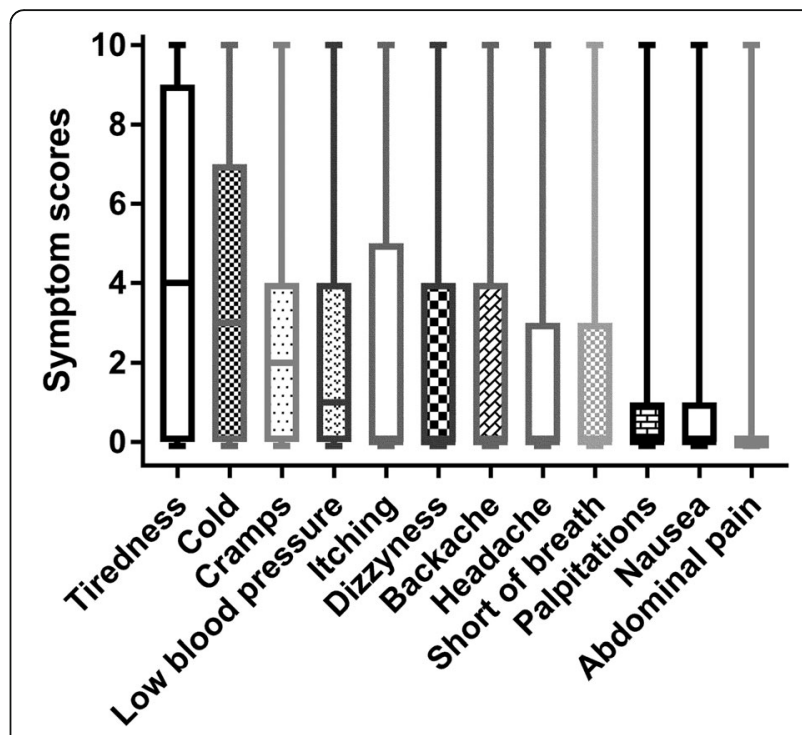

Fig. 1 Dialysis symptom scores: visual Likert scale of 0 to 10 . Results are expressed as median, interquartile and $95 \%$ limits

the dialysis session, but lower in those with a past medical history of aortic aneurysm or atheromatous reno-vascular disease and cancer (Table 3).

We performed univariate analysis and found that patient age was negatively associated with headache $(r=-$ $0.21, p<0.001)$, cramps $(r=-0.14, p<0.001)$, nausea $(r=-0.123, p<0.001)$, dizziness $(r=-0.13, p=0.001)$ and tiredness $(r=-0.11, p=0.007)$ (Table 2). Hand grip strength was negatively associated with backache $(r=-$ $0.20, p<0.001)$, tiredness $(r=-0.19, p<0.001)$, feeling cold $(r=-0.16, p<0.001)$, short of breath $(r=-0.15$, $p<0.001)$, abdominal pain $(r=-0.14, p<0.001)$, itching $(r=-0.11, p=0.006)$, nausea $(r=-0.11, p=0.014)$, and dizziness $(r=-0.09, p=0.027)$. Distress thermometer scores were positively associated with all symptoms as follows: tiredness $(r=0.35)$, backache $(r=0.32)$, dizziness $(r=0.28)$, cramps $(r=0.26)$, headache $(r=0.26)$, short of breath $(r=0.26)$, feeling cold $(r=0.24)$, abdominal pain $(r=0.24)$, itching $(r=0.91)$, palpitations $(r=0.22)$, nausea $(r=0.21)$ and low blood pressure $(r=0.18)$; all $p<0.001$.

We then analysed our data to determine the effect of gender. Time to recover was not different between men and women $(p=0.057)$, but distress thermometer scores were higher for women (median 4 (1-6) vs $3(0-6), p=0.041$ ), but after adjusting for multiple testing, this was then not significant. We analysed individual symptom scores, and again, after adjusting for multiple testing, the following symptoms were reported more frequently by female patients: headache median $1(0-3)$ vs $0 .(0-2)$, nausea $0(0-2)$ vs $0(0-0)$, backache $1(0-6)$ vs $0(0-3)$, dizziness $2(0-4)$ vs $0(0-3)$, tiredness $5.5(1.5-10)$ vs $3(0-7)$, feeling cold $5(0-10)$ vs $2(0-5)$ and low blood pressure $0(0-5)$ vs $0(0-3)$; all $p<0.05$. 


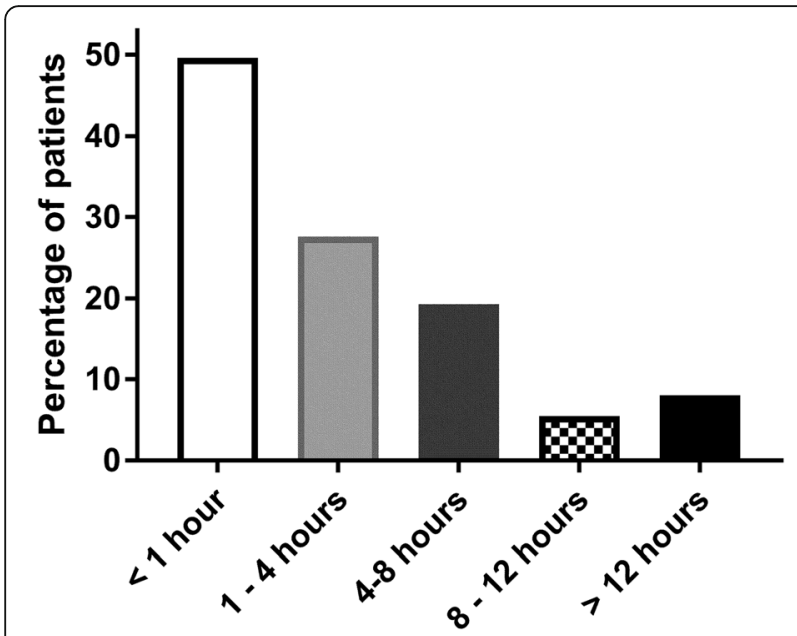

Fig. 2 Percentage of patients reporting time to recover after their haemodialysis session between less than an hour to more than $12 \mathrm{~h}$

We then divided the patient cohort according to dialysis symptom scores (Table 3). Ultrafiltration rates were calculated as the weight loss achieved with the dialysis session divided by the session time or by session time and pre-dialysis weight. Patients with symptomatic hypotension, when ultrafiltration rate was changed (21 patients), or had intravenous fluids (11 patients), were excluded from the analysis of ultrafiltration rates. We found that those patients who reported more dialysis-associated symptoms also reported taking a longer time to recover post-dialysis, and were more likely to be female, of younger age and of Asian ethnicity. Although Asian patients were older than Black patients, median age 70 (59-78) vs 60.5 (51-75) years, there was no difference with White patients 68 (56-79) years, but Asians had lower weight than Black patients (66.8 (55.8-76) vs $72.8(65-87) \mathrm{kg})$ but not different from

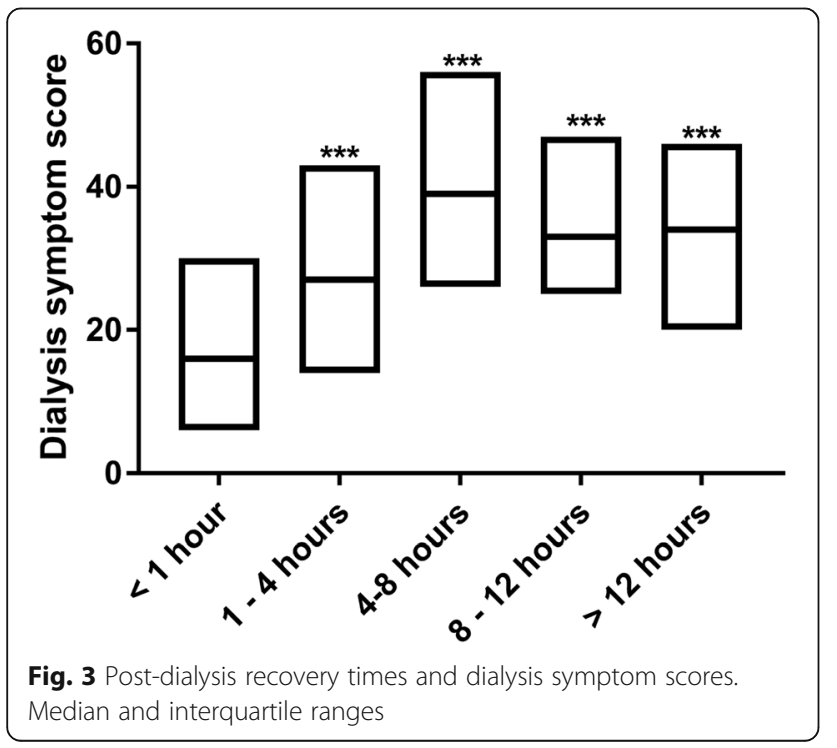

Table 2 Spearman univariate correlation with dialysis symptom scores

\begin{tabular}{lll}
\hline Variable & Univariate correlation $r$ & $p$ value \\
\hline Distress thermometer score & 0.46 & $<0.001$ \\
Time to recover post-dialysis & 0.38 & $<0.001$ \\
Female gender & 0.29 & $<0.001$ \\
Hand grip strength & -0.26 & $<0.001$ \\
Age & -0.31 & 0.001 \\
History of hypertension & 0.11 & 0.005 \\
Renal artery stenosis/aortic aneurysm & -0.11 & 0.008 \\
Urea reduction ratio & 0.10 & 0.012 \\
Fall in systolic blood pressure & 0.10 & 0.013 \\
History of cancer & -0.09 & 0.019 \\
C-reactive protein & 0.09 & 0.020 \\
\hline
\end{tabular}

White patients (69.3 (59.8-82.5) kg). However, urea reduction ratio was greater for Asian patients (76.1 (71.5-80)) compared to Whites (74.4 (68-78.8)) and Blacks (73.5 (68.4-77)), $p<0.05$. HGS was lower for Asians (16.0 (11.4-22.5) kg) vs White (18.8 (13.6-26.1) kg) vs Black (21.2 (14.2-29.7) kg), $p<0.05$.

Multivariable logistic regression models were compared to those with dialysis symptom scores above and below the median. When recovery time was excluded, the total dialysis symptom score was associated with younger age, higher distress thermometer score and hand grip strength (Table 4). Including recovery time, the same variables remained independently statistically significant as did a past history of a transient ischaemic attack. We found no association between the dialysate temperature and patients reporting feeling cold during dialysis $(r=-0.08, p=0.06)$, and similarly, prescription of hydroxy-3-methyl-glutaryl-coenzyme A 3 reductase inhibitors (statins) did not increase reporting of muscle cramps during dialysis (median score $2(0-4)$ vs $2(0-4)$ ).

\section{Discussion}

Although dialysis is a life-sustaining treatment for patients with end-stage kidney disease, dialysis imposes many restrictions both in terms of diet and also lifestyles, and as such, there is a relatively high prevalence of self-reported depression [28]. In addition to the perturbation of dialysis on normal daily activities, patients may experience a variety of symptoms during the dialysis session and then take time to recover from the dialysis treatment [2, 3]. Dialysis symptoms have variously been ascribed to the rapid reduction in plasma osmolality $[3,5]$ and the reduction in effective circulating plasma volume $[7,9,15]$. However, with technological improvements in the dialysis machines and dialysis water quality [1], more recently, reports have suggested that other factors, in terms of patient demographics and co-morbidity, and in 
Table 3 Patients divided into quartiles according to dialysis symptom scores. Months of dialysis treatment (vintage), ultrafiltration rate $\mathrm{mL} / \mathrm{kg} . \mathrm{h}$ (UFR), change in pre- vs post-systolic blood pressure in $\mathrm{mmHg}$ (SBP), dialysate temperature (Temp), dialysate sodium mmol/L (Dial Sodium), sodium gradient between serum and dialysate $\mathrm{mmol} / \mathrm{L}$ (Na gradient), urea reduction (URR), \% patients with recovery postdialysis $<1 \mathrm{~h}$ (recovery $<1 \mathrm{~h}$ ), C-reactive protein, glycated haemoglobin mmol/mol (HbA1c), pro $\mathrm{N}$ terminal brain natriuretic peptide (BNP), hand grip strength (HGS), distress thermometer (DT) and prescribed antihypertensive medications (BP meds)

\begin{tabular}{|c|c|c|c|c|}
\hline$\overline{\text { Variable }}$ & Quartile 1 & Quartile 2 & Quartile 3 & Quartile 4 \\
\hline Symptom score & $5(3-7)$ & $17(14-21)^{* * *}$ & $31(28-35)^{* * *}$ & $51(43-61)^{* * *}$ \\
\hline Male & 79.1 & 68.2 & 49.0 & $44.8^{* * *}$ \\
\hline Age, years & $68 \pm 14$ & $65 \pm 16$ & $65 \pm 17$ & $61 \pm 17^{* * *}$ \\
\hline Diabetic, \% & 44.3 & 44.3 & 46.2 & 50.0 \\
\hline White, \% & 43.9 & 50.9 & 45.5 & 31.8 \\
\hline Black, \% & 37.3 & 28.1 & 27.6 & 36.8 \\
\hline Asian, \% & 18.9 & 21.0 & 22.5 & $30.5^{*}$ \\
\hline Vintage months & $30.6(12.5-68.8)$ & $33.4(10.1-70.4)$ & $32.9(13.6-65.7)$ & $38.7(18.5-71.7)$ \\
\hline Weight, kg & $73.0 \pm 15.8$ & $76.3 \pm 16.0$ & $74.3 \pm 20.8$ & $71.0 \pm 20.6$ \\
\hline$\%$ weight loss & $2.2(1.4-3.0)$ & $2.1(1.3-2.9)$ & $2.2(1.6-3.1)$ & $2.4(1.2-3.0)$ \\
\hline UFR, mL/kg.h & $4.2(4.0-4.8)$ & $4.1(4.1-4.7)$ & $4.1(4.0-4.7)$ & $4.1(4.1-4.7)$ \\
\hline Session hours & $4.0(3.5-4.0)$ & $4.0(3.5-4.0)$ & $4.0(3.5-4.0)$ & $4.0(3.5-4.0)$ \\
\hline Temp., ${ }^{\circ} \mathrm{C}$ & $35.9 \pm 0.7$ & $35.8 \pm 0.7$ & $35.9 \pm 0.7$ & $35.9 \pm 0.7$ \\
\hline Dial, sodium & $137 \pm 1.0$ & $137 \pm 1.0$ & $137 \pm 1.0$ & $137 \pm 1.0$ \\
\hline $\mathrm{Na}$, gradient & $2(0$ to 4$)$ & $2(0$ to 4$)$ & $2(-1$ to 4$)$ & $2(-1$ to 4$)$ \\
\hline $\mathrm{Qb}, \mathrm{mL} / \mathrm{min}$ & $322 \pm 31$ & $323 \pm 31$ & $320 \pm 29$ & $322 \pm 39$ \\
\hline Dialyzer, $\mathrm{m}^{2}$ & $1.9 \pm 0.3$ & $2.0 \pm 0.3$ & $2.0 \pm 3.0$ & $1.9 \pm 0.3$ \\
\hline URR, \% & $73.8 \pm 8.9$ & $71.5 \pm 9.9$ & $73.4 \pm 8.5$ & $74.5 \pm 9.3$ \\
\hline$\%$ SBP > 20 down & 26.1 & 29.8 & 39 & 29.5 \\
\hline$\% \mathrm{SBP}>10$ up & 25.5 & 22.4 & $12.8^{*}$ & $14.8^{*}$ \\
\hline Haemoglobin, g/L & $108.5 \pm 14.5$ & $108.9 \pm 14.8$ & $109.4 \pm 14.5$ & $105.5 \pm 13.4$ \\
\hline Recovery $<1 \mathrm{~h}$ & 18.5 & 15.2 & $8.7^{* * *}$ & $7.2^{* * *}$ \\
\hline Albumin, $\mathrm{g} / \mathrm{L}$ & $38.4 \pm 4.5$ & $38.5 \pm 4.6$ & $38.2 \pm 4.1$ & $38.2 \pm 4.7$ \\
\hline $\mathrm{CRP}, \mathrm{mg} / \mathrm{L}$ & $5.0(2.0-10.0)$ & $6.0(3.0-11.0)$ & $7.0(3.0-11.0)$ & $6.0(2.0-11.0)$ \\
\hline $\mathrm{HbA1c}$ & $48(38-56)$ & $46(38-61)$ & $50(41-66)$ & $47(36-60)$ \\
\hline Glucose, mmol/L & $6.5(5.1-8.0)$ & $6.2(5.5-8.1)$ & $6.2(5.2-8.4)$ & $6.8(5.5-8.1)$ \\
\hline BNP, ng/L & 3130 (1678-9943) & 3385 (1357-8944) & $4253(1483-15,112)$ & $4072(1443-14,744)$ \\
\hline Frailty & $4(3-5)$ & $4(3-5)$ & $4(3-5)$ & $5(4-8)$ \\
\hline HGS, kg & $23 \pm 10$ & $22 \pm 11$ & $19 \pm 10^{* *}$ & $17 \pm 9^{* * *}$ \\
\hline DT, score & $1.0(0-3.0)$ & $2.5(0-5.0)^{* *}$ & $4.0(1.5-6.0)^{*}$ & $5.0(4.0-8.0)^{* * *}$ \\
\hline BP meds, \% & 67.4 & $50.3^{*}$ & 64.1 & 62.3 \\
\hline
\end{tabular}

Data expressed as number, percentage, mean \pm standard deviation, or median (interquartile range). ${ }^{*} p<0.05,{ }^{* *} p<0.01,{ }^{* * *} p<0.001$ vs quartile 1

particular psychosocial well-being have a greater influence on self-reported dialysis symptoms [17].

To determine the relative influence of individual components of the dialysis prescription and patient demographics and psychosocial factors on self-reported dialysis symptoms, we reviewed the responses over 600 patients. Some years ago, we introduced the distress thermometer score into our clinical practice [29]. This is a simple visual analogue scale which was initially developed as a rapid screening tool for assessing adjustment disorders and major depression in patients with cancer and then expanded to other conditions [30]. Compared to previous studies in haemodialysis patients, our haemodiafiltration cohort generally reported fewer dialysis symptoms and quicker post-treatment recovery times $[5,31]$. However, in keeping with recent reports, we found that fatigue was the most commonly reported symptom by our haemodialysis patients [32]. The next most commonly reported dialysis-associated symptom was one of feeling the cold. Our dialysis centres performed post-dilution 
Table 4 Backward logistic regression models of above and below dialysis symptom scores. Model 1 without and model 2 with time to recover post-dialysis. Adjusted Nagelkerke $r^{2}$ values 0.311 and 0.371 , respectively. Standard error of $\beta$ (StE $\beta$ ), odds ratio (OR), 95\% confidence limits of odds ratio 95\% CL. Hand grip strength (HGS), distress thermometer score (DT), history of transient ischaemic attack (TIA)

\begin{tabular}{lllllll}
\hline Variable & Beta $(\beta)$ & StE $\beta$ & Wald & OR & $95 \% \mathrm{CL}$ & $p$ value \\
\hline Model 1 & & & & & & \\
Age, years & -0.26 & 0.01 & 13.3 & 0.98 & $0.96-0.98$ & $<0.001$ \\
HGS, kg & -0.05 & 0.01 & 18.8 & 0.95 & $0.93-0.97$ & $<0.001$ \\
$\quad$ DT & 0.28 & 0.04 & 62.6 & 1.33 & $1.24-1.42$ & $<0.001$ \\
Model 2 & & & & & & \\
HGS, kg & -0.05 & 0.01 & 16.7 & 0.95 & $-.93-0.94$ & $<0.001$ \\
DT & 0.26 & 0.04 & 46 & 1.30 & $1.30-1.39$ & $<0.001$ \\
Time to recover & 0.48 & 0.01 & 23.7 & 1.61 & $1.33-1.95$ & $<0.001$ \\
Age, years & -0.02 & 0.01 & 7.9 & 0.98 & $0.97-0.99$ & 0.005 \\
TIA & 1.51 & 0.72 & 4.4 & 4.54 & $1.1-18.7$ & 0.036 \\
\hline
\end{tabular}

haemodiafiltration, and haemodiafiltration is recognised to reduce the risk of intra-dialytic hypotension, by increasing thermal losses, which may explain the relatively high prevalence of feeling cold compared to reports from patients treated by haemodialysis [33], although there was no statistical association between the dialysate temperature and patient reports of feeling cold. Cramps were the third most common symptom reported. Previous studies have suggested that the choice of lower dialysate sodium concentrations may increase the prevalence of cramps [7]. However, we found no difference in the prescription of dialysate sodium or the gradient between serum sodium and dialysate sodium and self-reported symptoms. An earlier dialysis outcomes study reported an association between dialysate sodium selection and post-dialysis recovery times; however, in more than $50 \%$ of cases, patient data was not available for the analysis, and there was no data collected on dialysate temperature [33].

Similarly, we found no difference in the prescription of dialysate potassium and dialysis-associated symptoms [8]. Symptoms associated with low blood pressure were then next most commonly reported, and several previous studies have reported a strong association between ultrafiltration rates and post-dialysis fatigue [15, 34, 35]. However, these studies were typically reporting much high ultrafiltration rates of $>9 \mathrm{~mL} / \mathrm{kg}$.h compared to our patients, and we found no association with changes in systolic blood pressure or pre-dialysis NT-proBNP. Compared to previous studies, our patients reported relatively fewer symptoms $[15,16,35]$. This may have been due to the use of convective clearance with haemodiafiltration rather than conventional haemodialysis [13], or the colder dialysates [9], or lower ultrafiltration rates used in our study cohort [15, 33-35].

However, there was a significant association between the distress thermometer scores and both dialysis symptom scores and the time taken to recover post-dialysis. Other studies have also observed an effect of patient psychological distress on self-reported depression and the time to recovery after dialysis [15-17]. Previous studies have reported an association between longer post-dialysis recovery times and a history of psychiatric disorders, in particular depression [33].

Although women reported an increased number of symptoms with dialysis, particularly headache, nausea, abdominal pain, dizziness, fatigue and feeling the cold, in keeping with other studies [33], on multivariable testing, gender was not statistically significant.

Interestingly, we found no effect of previous myocardial infarction, coronary artery bypass surgery or cardiac stenting and patient-reported symptoms, whereas patients with a history of cancer and aortic aneurysm and reno-vascular disease who had undergone stenting reported fewer symptoms. Whether this represents that those patients who may have had more potentially stressful experiences report fewer symptoms remains to be determined. In keeping with previous studies, our older patients reported fewer symptoms and it has been suggested that older patients are more accepting treatments which restrict life-style than younger patients [17].

We did not observe an effect of ultrafiltration rates and dialysis-associated symptoms; however, our ultrafiltration rates were much lower than those previously reported with increased post-dialysis recovery times [15, 33, 35]. However, patients with a history of the transient ischaemic attack reported more intra-dialytic symptoms, and these may have been more susceptible to changes in brain blood flow and osmolality $[3,5]$. In addition, both female and Asian patients reported more symptoms than patients from other ethnicities, and Asian patients had lower body weight but had higher urea reduction ratios, which may have predisposed to greater relative changes in serum osmolality $[3,5]$.

We found that younger patients and those with greater HGS reported more dialysis-associated symptoms. This would suggest that younger healthier patients suffered more symptoms. This apparent paradox has been previously reported and may be due to younger patients having greater difficulty in adapting to dialysis in terms of changes in social and financial circumstances and in comparison to friends and peers, whereas older patients are more acceptable to chronic ill health [36]. This is supported by the association between distress thermometer scores and patient-reported symptoms [37]. Thus, underlying psychological distress is a major factor in patient self-reported symptoms. 
Compared to previous studies, our patients treated by haemodiafiltration reported fewer intra-dialytic symptoms and shorter post-treatment recovery times. Haemodiafiltration may offer advantages in terms of intra-dialytic blood pressure stability due to the additional cooling effect and also the use of ultra-pure dialysate water [38]. However, both patients with greater psychological distress as assessed by the distress thermometer and also those smaller female and Asian patients reported more symptoms, suggesting that in addition to psychological factors, the greater reduction in urea contributed to dialysis-associated symptoms and delayed post-dialysis recovery.

\section{Abbreviations}

CRP: C-reactive protein; NT-proBNP: N terminal pro-brain natriuretic peptide

\section{Acknowledgements}

Drs. Suree Yoowannakul and Kamonwan Tangvoraphonkchai were in receipt of the International Society of Nephrology training scholarships. The authors thank the patients for their cooperation.

\section{Funding}

None

\section{Availability of data and materials}

Data is with Royal Free Hospital audit.

\section{Authors' contributions}

$A D$ registered the audit. SY and $K T$ handed out and collected the questionnaires. $A D$ analyzed the data. All authors contributed to the first draft and approved the final draft of the manuscript.

\section{Ethics approval and consent to participate}

This retrospective audit was approved by the Royal Free Hospital and complied with the UK National Health Service (NHS) guidelines for clinical audit and service development and met with the approval from the Health Research Authority (HRA). In keeping with the UK guidelines, all patient data were anonymised prior to analysis (https://www.hra.nhs.uk).

\section{Consent for publication}

All authors agreed on the publication of this study.

\section{Competing interests}

The authors declare that they have no competing interests.

\section{Publisher's Note}

Springer Nature remains neutral with regard to jurisdictional claims in published maps and institutional affiliations.

\section{Author details}

'Division of Nephrology, Department of Medicine, Bhumibol Adulyadej Hospital, Klong Thanon, Saimai, Bangkok 10220, Thailand. ${ }^{2}$ Faculty of Medicine, Mahasarakham University, Maha Sarakham, Thailand. ${ }^{3} \mathrm{UCL}$ Department of Nephrology, Royal Free Hospital, Rowland Hill Street, London NW3 2PF, UK.

Received: 11 February 2019 Accepted: 4 April 2019

Published online: 23 April 2019

\section{References}

1. Davenport A. Using dialysis machine technology to reduce intradialytic hypotension. Hemodial Int. 2011;15 Suppl 1:S37-42.

2. Lindsay RM, Heidenheim PA, Nesrallah G, Garg AX, Suri R. Daily Haemodialysis Study Group London Health Sciences Centre. Minutes to recovery after a haemodialysis session: a simple health-related quality of life question that is reliable, valid, and sensitive to change. Clin J Am Soc Nephrol. 2006;1 (5):952-9.

3. Benna P, Lacquaniti F, Triolo G, Ferrero P, Bergamasco B. Acute neurologic complications of hemodialysis. Study of 14,000 haemodialyses in 103 patients with chronic renal failure. Ital J Neurol Sci. 1981;2(1):53-7.

4. Caplin B, Kumar S, Davenport A. Patients' perspective of haemodialysisassociated symptoms. Nephrol Dial Transplant. 2011;26(8):2656-63.

5. Arieff Al. Dialysis disequilibrium syndrome: current concepts on pathogenesis and prevention. Kidney Int. 1994;45(3):629-35.

6. Davenport A, Cox C, Thuraisingham R. Achieving blood pressure targets during dialysis improves control but increases intradialytic hypotension. Kidney Int. 2008;73(6):759-64.

7. Ogden DA. A double-blind crossover comparison of high and low sodium dialysis. Proc Clin Dial Transplant Forum. 1978;8:157-65.

8. Harford A, Gul A, Cumber S, Paine S, Schrader R, Trujillo N, Zager P. Low dialysate potassium concentration is associated with prolonged recovery time. Hemodial Int. 2017;21 Suppl 2:S27-32.

9. Marcén R, Quereda C, Orofino L, Lamas S, Teruel JL, Matesanz R, Ortuño J. Hemodialysis with low-temperature dialysate: a long-term experience. Nephron. 1988;49(1):29-32

10. Orasan OH, Saplontai AP, Cozma A, Racasan S, Kacso IM, Rusu CC, Moldovan D, Tirinescu D, Potra A, Patiu IM, Orasan RA. Insomnia, muscular cramps and pruritus have low intensity in hemodialysis patients with good dialysis efficiency, low inflammation and arteriovenous fistula. Int Urol Nephrol. 2017:49(9):1673-167.

11. Garg AX, Suri RS, Eggers P, Finkelstein FO, Greene T, Kimmel PL, Kliger AS, Larive B, Lindsay RM, Pierratos A, Unruh M, Chertow GM, Frequent Hemodialysis Network Trial Investigators. Patients receiving frequent haemodialysis have better health-related quality of life compared to patients receiving conventional haemodialysis. Kidney Int. 2017;91(3):746-54

12. Davenport A, Gura V, Ronco C, Beizai M, Ezon C, Rambod E. A wearable haemodialysis device for patients with end-stage renal failure: a pilot study. Lancet. 2007;370(9604):2005-10.

13. Nakagawa S. Multifactorial evaluation of hemofiltration therapy in comparison with conventional hemodialysis. Artif Organs. 1980;4(2):94-102.

14. Caplin B, Alston H, Davenport A. Does online haemodiafiltration reduce intra-dialytic patient symptoms? Nephron Clin Pract. 2013;124(3-4):184-90.

15. Sklar A, Newman N, Scott R, Semenyuk L, Schultz J, Fiacco V. Identification of factors responsible for post-dialysis fatigue. Am J Kidney Dis. 1999:34(3):464-70.

16. Bossola M, Di Stasio E, Antocicco M, Silvestri P, Tazza L. Variables associated with time of recovery after haemodialysis. J Nephrol. 2013;26(4):787-92.

17. Davenport A, Guirguis A, Almond M, Day C, Chilcot J, Da Silva Gane M, Fineberg N, Friedl K, Spencer B, Wellsted D, Farrington K. Post-dialysis recovery time is extended in patients with greater self-reported depression screening questionnaire scores. Hemodial Int. 2018;22(3):369-76.

18. Lopes GB, Silva LF, Pinto GB, Catto LF, Martins MT, Dutra MM, Lopes AA. Patient's response to a simple question on recovery after haemodialysis session strongly associated with scores of comprehensive tools for quality of life and depression symptoms. Qual Life Res. 2014;23(8):2247-56.

19. Alston H, Burns A, Davenport A. Loss of appendicular muscle mass in haemodialysis patients is associated with increased self-reported depression, anxiety and lower general health scores. Nephrology (Carlton). 2018;23(6):546-51.

20. Davies SJ, Phillips L, Naish PF, Russell Gl. Quantifying comorbidity in peritoneal dialysis patients and its relationship to other predictors of survival. Nephrol Dial Transplant. 2002;17(6):1085-92.

21. Walker SR, Brar R, Eng F, Komenda P, Rigatto C, Prasad B, Bohm CJ, Storsley $\sqcup$, Tangri N. Frailty and physical function in chronic kidney disease: the CanFIT study. Can J Kidney Health Dis. 2015;2:32 PMID: 26346754.

22. Omichi Y, Srivareerat M, Panorchan K, Greenhall GH, Gupta S, Davenport A. Measurement of muscle strength in haemodialysis patients by pinch and hand grip strength and comparison to lean body mass measured by multifrequency bio-electrical impedance. Comparison to lean body mass measured by multifrequency bio-electrical impedance. Ann Nutr Metab. 2016;68(4):268-75

23. Booth J, Pinney J, Davenport A. N-terminal proBNP--marker of cardiac dysfunction, fluid overload, or malnutrition in haemodialysis patients? Clin J Am Soc Nephrol. 2010;5(6):1036-40.

24. Tangvoraphonkchai K, Riddell A, Davenport A. Platelet activation and clotting cascade activation by dialyzers designed for high volume online hemo-diafiltration. Hemodial Int. 2018;22(2):192-200. 
25. Davenport A. Low-molecular-weight heparin as an alternative anticoagulant to unfractionated heparin for routine outpatient haemodialysis treatments. Nephrology (Carlton). 2009;14(5):455-61.

26. Sandhu E, Crawford C, Davenport A. Weight gains and increased blood pressure in outpatient haemodialysis patients due to change in acid dialysate concentrate supplier. Int J Artif Organs. 2012;35(9):642-7.

27. Davenport A. Negative dialysate to sodium gradient does not lead to intracellular volume expansion post haemodialysis. Int J Artif Organs. 2010; 33(10):700-5.

28. Friedli K, Guirguis A, Almond M, Day C, Chilcot J, Da Silva-Gane M, Davenport A, Fineberg NA, Spencer B, Wellsted D, Farrington K. Sertraline versus placebo in patients with major depressive disorder undergoing hemodialysis: a randomized, controlled feasibility trial. Clin J Am Soc Nephrol. 2017. https://doi.org/10.2215/CJN.02120216 PMID: 28126706.

29. Camilleri S, Chong S, Tangvoraphonkchai K, Yoowannakul S, Davenport A. Effect of self-reported distress thermometer score on the maximal handgrip and pinch strength measurements in hemodialysis patients. Nutr Clin Pract. 2017;32(5):682-6.

30. Mitchell AJ, Morgan JP, Petersen D, Fabbri S, Fayard C, Stoletniy L, Chiong J. Validation of simple visual-analogue thermometer screen for mood complications of cardiovascular disease: the emotion thermometers. J Affect Disord. 2012;136(3):1257-63.

31. Rayner HC, Zepel L, Fuller DS, Morgenstern H, Karaboyas A, Culleton BF, Mapes DL, Lopes AA, Gillespie BW, Hasegawa T, Saran R, Tentori F, Hecking M, Pisoni RL, Robinson BM. Recovery time, quality of life, and mortality in hemodialysis patients: the Dialysis Outcomes and Practice Patterns Study (DOPPS). Am J Kidney Dis. 2014;64(1):86-94.

32. Tong A, Manns B, Wang AYM, Hemmelgarn B, Wheeler DC, Gill J, Tugwell P, Pecoits-Filho R, Crowe S, Harris T, Van Biesen W, Winkelmayer WC, Levin A, Thompson A, Perkovic V, Ju A, Gutman T, Bernier-Jean A, Viecelli AK, O'Lone E, Shen J, Josephson MA, Cho Y, Johnson DW, Sautenet B, Tonelli M, Craig JC, SONG Implementation Workshop Investigators. Implementing core outcomes in kidney disease: report of the Standardized Outcomes in Nephrology (SONG) implementation workshop. Kidney Int. 2018. https://doi. org/10.1016/j.kint.2018.08.018 PMID: 30360959.

33. van der Sande FM, Kooman JP, Konings CJ, Leunissen KM. Thermal effects and blood pressure response during postdilution hemodiafiltration and hemodialysis: the effect of amount of replacement fluid and dialysate temperature. J Am Soc Nephrol. 2001;12(9):1916-20.

34. Bossola M, Di Stasio E, Monteburini T, Parodi E, Ippoliti F, Cenerelli S, Santarelli S, Nebiolo PE, Sirolli V, Bonomini M, Antocicco M, Zuccalà G, Laudisio A. Recovery time after hemodialysis is inversely associated with the ultrafiltration rate. Blood Purif. 2018:1-7. https://doi.org/10.1159/000492919 [Epub ahead of print]. PMID: 30231240.

35. Hussein WF, Arramreddy R, Sun SJ, Reiterman M, Schiller B. Higher ultrafiltration rate is associated with longer recovery time in patients undergoing conventional haemodialysis. Am J Nephrol. 2017;46:3-10.

36. Chilcot J, Norton S, Wellsted D, Davenport A, Firth J, Farrington K. Distinct depression symptom trajectories over the first year of dialysis: associations with illness perceptions. Ann Behav Med. 2013:45(1):78-88.

37. Davenport A, Guirguis A, Almond M, Day C, Chilcot J, Da Silva Gane M, Fineberg N, Friedl K, Spencer B, Wellsted D, Farrington K. Postdialysis recovery time is extended in patients with greater self-reported depression screening questionnaire scores. Hemodial Int. 2018;22(3):369-76. https://doi. org/10.1111/hdi.12642 MID: 29461016

38. Tattersall JE, Ward RA, EUDIAL group. Online haemodiafiltration: definition, dose quantification and safety revisited. Nephrol Dial Transplant. 2013;28(3):542-50.

Ready to submit your research? Choose BMC and benefit from:
- fast, convenient online submission
- thorough peer review by experienced researchers in your field
- rapid publication on acceptance
- support for research data, including large and complex data types
- gold Open Access which fosters wider collaboration and increased citations
- maximum visibility for your research: over 100M website views per year
At BMC, research is always in progress.
Learn more biomedcentral.com/submissions

